\title{
Elementary visual hallucinations in migraine and epilepsy
}

\author{
C P Panayiotopoulos
}

\begin{abstract}
A comparison of the elementary visual hallucinations of 50 patients with migraine and 20 patients with occipital epileptic seizures showed that epileptic seizures are predominantly multicoloured with circular or spherical patterns as opposed to the predominantly black and white linear patterns of migraine. This simple clinical symptom of the elementary visual hallucinations may be helpful in distinguishing between classic or basilar migraine and visual partial epileptic seizures, particularly in children. Claims that epileptic seizures are triggered or caused by migraine may be artificial, reflecting problems in the differential diagnosis between the two diseases.
\end{abstract}

(F Neurol Neurosurg Psychiatry 1994;57:1371-1374)

St Thomas' Hospital, London SE1 7EH, UK C P Panayiotopoulos

Correspondence to:

Dr C P Panayiotopoulos,

Department of Clinical

Neurophysiology and

Epilepsy, St Thomas'

Hospital, London SE1 7EH,
UK.

Received 28 January 1994

and in revised form

6 April 1994

Accepted 25 May 1994

Elementary visual hallucinations are common in the prodrome phase of classic and basilar migraine and in partial seizures originating from the occipital lobes. ${ }^{12}$ Although migraine and epilepsy are often easy to diagnose there are cases, mainly children, with considerable difficulties in their differentiation. ${ }^{1-10}$ Elementary visual hallucinations, particularly

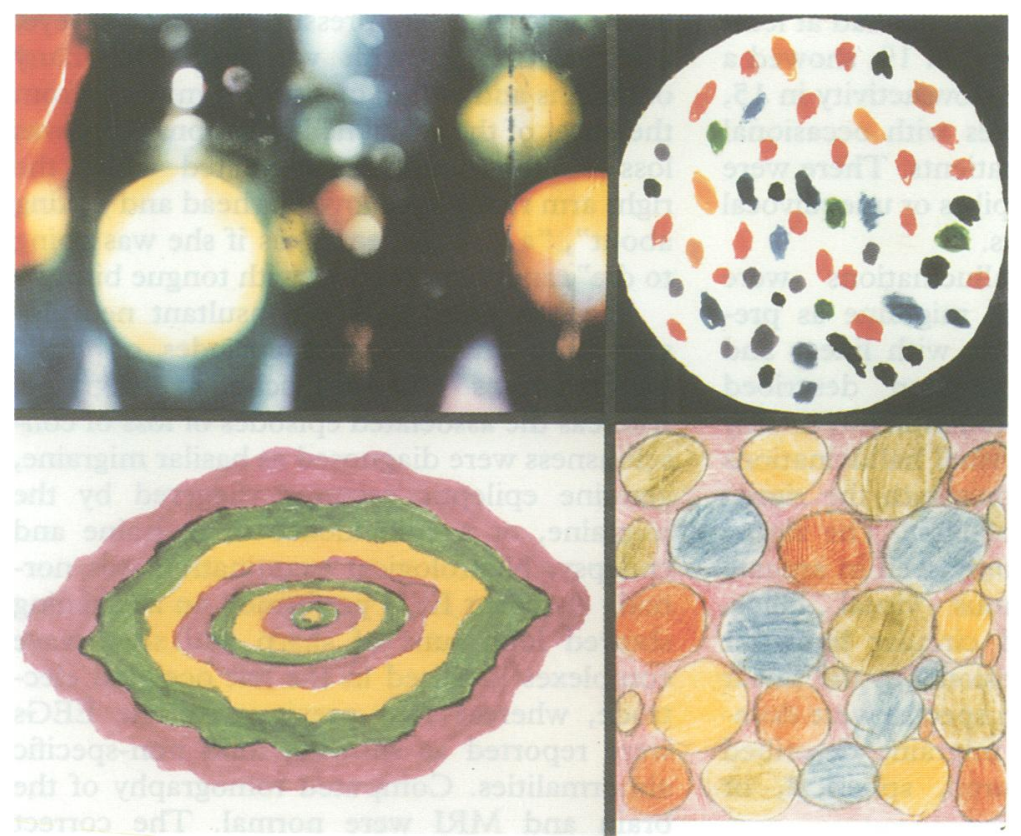

Visual illusions of occipital lobe epilepsy as perceived and illustrated by the patients: case 1 (top left), case 4 (top right), case 3 (bottom left), case 2 (bottom right). when combined with headache, vomiting or blindness are more likely to be diagnosed as characteristic of migraine despite the fact that they are also common ictal manifestations of occipital lobe seizures. ${ }^{1}$ If such ictal epileptic migraine-like symptoms are followed by loss of consciousness and convulsions, the diagnosis of seizures triggered by migraine or basilar artery migraine ${ }^{11}$ is often made. $^{23}$

Children with benign childhood epilepsy and occipital paroxysms (BCEOP) have been reported as having basilar migraine with epileptic seizures ${ }^{3}$ before BCEOP was established as a benign epileptic syndrome. ${ }^{47}$ Also, it is possible that reports of migraine evolving to seizures ${ }^{2312}$ may reflect the difficulties in recognising epileptic seizures of the occipital lobes, which often present with symptoms imitating migraine (visual hallucinations, headache, and vomiting)

Comparisons of the elementary visual hallucinations between 50 patients with migraine and 20 patients with occipital lobe seizures were prospectively made. Four patients with visual partial seizures who illustrated their elementary visual hallucinations are presented.

\section{Materials and methods}

Patients and methods of investigations including comprehensive EEG studies as well as brain imaging when appropriate, have been described elsewhere. ${ }^{1457}$ All patients from 1980 to 1993 with elementary visual hallucinations due either to migraine or epilepsy have been prospectively and systematically interrogated regarding the quality of their hallucinations. They were particularly asked whether their hallucinations were predominantly black and white or coloured and whether the patterns seen were predominantly linear/zigzag or circular/spherical.

Four recently seen patients with visual epileptic seizures were asked to illustrate their elementary visual hallucinations (figure).

\section{TERMINOLOGY}

In reviewing the medical records of patients I was impressed that the description of visual hallucinations were often abbreviated in terms such as fortification spectrum, teichopsia, scintillating scotoma, phosphenes, and their variations. Their meaning did not always represent the actual descriptions. This has been emphasised by Plant ${ }^{13}$ in a detailed and well documented historical review of the origin of the term fortification spectra in migraine. The 
migrainous elementary visual hallucinations are called fortifications because of their similarities to the bastioned, star patterned, pentagonal fortifications and not of the castellated appearances of battlements.

I was startled by a singular shadowy appearance at the outside corner of the field of vision of the left eye. It gradually advanced into the field of view and then appeared to be a pattern in straight-lined angular forms, very much in general aspects like the drawing of a fortification, with salient and re-entering angles, bastions, and ravelins with some suspicion of faint lines of colour between the dark lines.

Sir JFW Herschel (1866) ${ }^{14}$

(Note: a bastion is a projecting part of a fortification, consisting of an earthwork in the form of an irregular pentagon, having its base in the main line or at an angle of the fortification. A ravelin is an outwork consisting of two faces that form a salient angle, situated in front of the bastions.)

Spectrum is also used by Gowers ${ }^{15}$ to mean apparition and not a coloured band of light. ${ }^{13}$

The name 'Teichopsia' (teichos = town wall, opsis = vision) to represent the bastioned form of transien hemiopsia which I have been describing, not without a reminiscence of some words of Tennyson's:

as yonder walls

Rose slowly to a music slowly breathed, A cloud that gathered shape

Airy $(1870)^{16}$

Scintillating $\quad($ scintilla $=$ spark $)$ scotoma (skotos = darkness) is also used because of the sparking appearance of the visual hallucinations of migraine (brilliant flashes of light in the periphery of dark areas in the visual fields).

Photopsias $\quad($ phos $=$ light,$\quad$ opsis $=$ vision $)$ are unformed flashes of light and sparks.

\section{Results}

There were 47 patients with classic and three with basilar migraine. They were aged 7-60 years. Forty four of these patients had at least one EEG, which was normal in 19 , showed a moderate excess of diffuse slow activity in 15, and paroxysmal theta waves with occasional sharp components in 10 patients. There were no patients with occipital spikes or unequivocal epileptogenic abnormalities.

Elementary visual hallucinations were described by patients with migraine as predominantly black and white with linear and zigzag patterns. Patients often described colours, which were not predominant, mainly in the periphery of their visual hallucinations or faint coloured lines along with the zigzag bright streaks or flashes of light. The zigzag shaped lights were commonly seen in arcuate shape across homonymous visual fields. Rarely patients described circular lights or rounded obscuration of vision but the linear patterns of the fortification spectra were dominating. No patient with migraine described predominantly multicoloured, spherical, or circular patterns.

In 20 patients (age range 7-47 years) with idiopathic or symptomatic visual partial seizures, hallucinations were predominantly multicoloured, with circular or spherical 而atterns. Two patients described predominantly square and a third patient triangular milticoloured patterns but no black and white or zigzag patterns. In another patient Fith symptomatic seizures the attack would start with a "ball of bright red in the right vâsual field which would move to the right side" wollowed by deviation of the eyes marching to simple motor partial and secondary ge alised tonic-clonic seizures. None of the patients had the zigzag linear, black and wite patterns of the migraine prodrome. क्No patient described visual hallucinations sireilar to the scintillating scotoma, photopsias, fo ification spectra, or teichopsias of migraine. Three had BCEOP, nine symptonatic seizures due to occipital lobe lesions; twक्ष an unusual form of photosensitivity (which in one of them was associated with absence seizures and eyelid fluttering) and occipital lobe epilepsy; no underlying cause was found in the remaining six patients. The cling cal diagnosis of epilepsy was unequivocally epnfirmed in all patients either because of spike and slow wave activity in the occipital regions or structural occipital lobe lesions.

The histories of four patients who have provided illustrations of their hallucinations figure) are as follows:

CASE 1

This woman, born in 1969 , was referre to me in 1992 with a diagnosis of migraine associated with epilepsy. At 9 years of age $\$$ he started to have frequent episodes of visual hallucinations and headache on awake iing between 530 and 630 am every one to Iwo months. The visual hallucinations consiofted of vivid, flashing multicoloured lights and \%ैircular patterns that occupied her visual fields and obscured her vision (figure). Severe lateral headache followed one to two minutes later, described like pressure behind one $\frac{\mathrm{F} y e}{\mathrm{~s}}$, often associated with vomiting. On many occasions and within one to two minutes from the onset of the visual hallucinations there ¿was loss of consciousness associated with right arm rising up above her head and jerking about", "a strange feeling as if she was going to die", and "convulsions with tongue biting".

She was seen by five consultant neurglogists who attributed the episodes of visual hallucinations and headache to migraine, whereas the associated episodes of loss of \&Onsciousness were diagnosed as basilar migrathe, genuine epileptic seizures triggered by cthe migraine, or a coincidence of migraine Gind epilepsy. Neurological examination was pormal. A recent EEG performed on awakeñing showed long runs of sharp and slow wave complexes localised in the left occipital efectrode, whereas four previous routine EfGs were reported as showing mild non-spe abnormalities. Computed tomography of the brain and MRI were normal. The corfect diagnosis is visual partial seizures with gecondary generalisation. 
CASE 2

This boy was born in 1980 . At the age of 10 years he had frequent visual disturbances lasting for 10-30 seconds, rare and brief episodes of complete blindness without warning or impairment of consciousness, and four episodes of loss of consciousness without convulsions, that lasted one to two minutes.

Simple visual hallucinations (he called them visions) were described as follows: "I saw my 'visions' in my right eye and they draw my right eye and my head to the right. It looked like a rectangle filled with coloured small circles. This time I saw the colours: they were blue, green, red, and yellow... They are always in my right eye and draw my right eye and my head to the right."

One of the four episodes of loss of consciousness was witnessed by a physician who described it as "clumsiness, vacant, unresponsive for a minute or so. No convulsions." Another one was described by his parents: "He was next to us in a shop. We heard a bang and saw him on the ground. He was pale. He was out for a few seconds."

Pronounced fixation-off sensitivity ${ }^{7}$ was demonstrated with video-EEG, which showed continuous, high amplitude, occipital paroxysms only under conditions where fixation and central vision were eliminated. ${ }^{7}$ His brain CT was normal. All episodes resolved with carbamazepine (100 $\mathrm{mg}$ twice daily) in a three year follow up period.

The diagnosis is late onset benign childhood epilepsy with occipital paroxysms.

CASES 3 AND 4

These men, aged 22 and 36, have intractable symptomatic visual partial seizures due to occipital lobe infarcts as demonstrated on MRI.

\section{Discussion}

This report shows that elementary visual hallucinations of visual partial epileptic seizures have different characteristics to those of migraine. Visual epileptic seizures are predominantly multicoloured with circular/ spherical patterns as opposed to the predominantly black and white zigzag linear patterns described by patients with migraine. These findings are supported by other reports where elementary visual hallucinations of epileptic seizures are described as multicoloured and circular: "millions of small, very bright, coloured, mainly blue and green, circular spots of light", "moving multicoloured flashing spots", 6 "single or multiple coloured spots that often rotated", "coloured balls of light in which red predominates"12 "brightly coloured discs",9 "phosphenes described as round, coloured, flickering luminous shapes". ${ }^{17}$

To test the clinical validity of this finding I asked other physicians with an interest in migraine and epilepsy to notify me of any patients who did not justify the observation that visual epileptic seizures are predominantly multicoloured and spherical/circular whereas the migraine hallucinations are pre- dominantly black and white with linear patterns. There was a child aged 10 years w had multicoloured hallucinations with sphefical patterns; all other clinical symptoms were characteristic of classic migraine and his EE⿱ was normal. Conversely, a case with symptematic seizures due to a low grade astrocytoria may have had seizures with predominan black and white patterns. Another patient häd visual epileptic seizures with hexagonal po chromatic patterns.

Case 1 of this report illustrates that cluste of symptoms such as elementary visual halluenations, and episodes of blindness, headacke, and vomiting are more likely to be diagnose्]d as migraine. This is also typical of most che dren with the late onset variant of childhogd epilepsy with occipital paroxysms, ${ }^{1-10}$ illi\&trated by case 2 .

Reported cases of epileptic seizures triggered by migrainous attacks may reflect diffculties in differentiating the prodromal visut phenomena of migraine from the elementäy visual hallucinations of epileptic seizures. 귱 review of relevant reports often shows that the visual hallucinations were either poorly described or that they consisted of "circular lights of many colours"-that is, they were probably visual partial seizures. A widely cited paper on the relation of migraine and epilepsy is by Basser" ${ }^{12}$; two cases "where the same or similar aura leads sometimes to migraine awd sometimes to epilepsy" are relevant to my findings. One of these patients (case 3 in report) ${ }^{12}$ was a child with typical absen\&e seizures as indicated by his EEG with "high voltage spike and wave complexes" and brikf clinical events of "twitching of the eyelids". There is also a complex paroxysmal sympto matology before the child "sees a bright shi ing blue spot", which leads either to headache and vomiting (interpreted as migraine) or topa "grand mal seizure". The other patient, a year old woman (case 4 in his report) ho्gd epileptic seizures in childhood preceded by "large blobs of coloured light" and develope्ed in adult life recurrent headaches which follow visual disturbances of "lines and strakes 吾f light that are white" not accompanied by epileptic fits. ${ }^{12}$

The predominantly black and white, linegir zigzag patterns of migraine are illustrated all relevant books of migraine and reflected on their terminology (scintillating scotoma, fortification spectra, teichopsias). ${ }^{14-16}$ That colouis may be seen in the course of migrainous visugl hallucinations has been described well even before the time of Gowers. ${ }^{13-16}$ Spots, circles, and beads with or without colours may also $\mathrm{Ee}$ seen by some patients with migraine. ${ }^{18}$ Colour and circular/spherical patterns in migraire, however, are considered as part of the scint lating scotoma and teichopsias and not as the predominant feature of the migrainous visuel hallucinations. Conversely, none of the patients with occipital epileptic seizures experienced the predominantly black and whife scintillating scotoma and fortification spectra of migraine. This has previously beên reported in patients with symptomatic visual 
partial seizures. ${ }^{19}$ Furthermore, a recent exhibition of the artistic impression of migraine, organised by the British Migraine Association and Glaxo, showed that although most of the visual hallucinations were painted with colours, all but one had linear, mainly zigzag patterns. None could be confused with the illustrations presented in the figure in this report.

In conclusion, the characteristics of the elementary visual hallucinations are often different in migraine and epileptic seizures. This may be a useful clinical guide in the differential diagnosis of migraine and epilepsy, especially when combined with other clinical details (visual hallucinations in seizures are brief, mostly lasting for one to two minutes, onset is always on the same side, and headache is rarely throbbing; vomiting may be common in both) and laboratory findings (occipital paroxysms in BCEOP, generalised spike and slow waves in idiopathic generalised epilepsies, focal EEG findings, and structural abnormalities on brain imaging in symptomatic epilepsies). There are more differences in the chronological sequence and the quality of the symptoms between migrainous and epileptic events but this is beyond the purpose of this report. ${ }^{1}$

Furthermore, it is suggested that the concept of epileptic seizures triggered by migrainous events should be re-evaluated; most reported cases are probably genuine visual partial epileptic seizures imitating migraine. Elementary visual hallucination should better be described rather than abbreviated in terms such as scintillating, fortification, and teichopsia, which are often confusing. More importantly elementary visual hallucinations, blindness, headache, and vomiting, which are common manifestations of occipital lobe epilepsies, should not be unquestionably equated with migraine. ${ }^{1}$

I am grateful to Dr D Bates, consultant neurologist, Dr A Goumas-Kartalas, neuropsychiatrist, Dr G Plant, consultant neurologist, Dr C Stern, consultant paediatrician, and Dr Z neurologist, Dr C Stern, consultant paediatrician, and Dr Z Zaiwalla, consultant in clinical neurophysiology for helping me patients. Glaxo UK provided me with illustrations of migrainous visual hallucinations from the exhibition of the antistic impression of migraine organised by the British Migmaine Association. British Telecom Charitable Organisation an\&The Special Trustees of St Thomas' Hospital have supported us with generous grants for our clinical research on epilepsies

1 Panayiotopoulos CP. Difficulties in different migraine and epilepsy based on clinical and EEGCandings. In: Andermann F, Lugaresi E, eds. Migraineoand epilepsy. London: Butterworth Publishers Inc, 87 : epilepsy.

2 Andermann F. Clinical features of migraine-epilepsy dromes. In: Andermann F, Lugaresi E, eds. Mi aine and epilepsy. London: Butterworth Publishers Inc, 197 : and epile. 30 .

3 Camfield PR, Metrakos K, Andermann F. B silar migraine, seizures, and severe epileptiform EEG aßpormalities. Neurology 1978;28:584-8.

4 Panayiotopoulos CP. Basilar migraine? seizures, $\bar{C}_{\text {and }}$ severe epileptic EEG abnormalities. Neurology 19;30: 1122-5.

5 Panayiotopoulos CP. Inhibitory effect of central visi occipital lobe seizures. Neurology 1981;31:1331-3. ¿

6 Gastaut H, Zifkin BG. Benign epilepsy of childhoodawith occipital spike and wave complexes. In: Andermafin F, Lugaresi E, eds. Migraine and epilepsy. Longon: Butterworth Publishers Inc, 1987:47-81.

7 Panayiotopoulos CP. Benign childhood epilepsy $\overrightarrow{\text { with }}$ occipital paroxysms: A 15-year prospective clinicaliand electroencephalographic study. Ann Neurol 1989,26: 51-6.

8 Terzano MG, Manzoni GC, Parrino L. Benign ep with occipital paroxysms and migraine: The question of intercalated attacks. In: Andermann F, Lugaresi E C ds. Migraine and epilepsy. London: Butterworth Publishers Inc, 1987:83-96.

9 Aicardi J, Newton R. Clinical findings in children $-\overrightarrow{w i t h}$ occipital spike wave complexes suppressed by eye opening. In: Andermann F, Lugaresi E, eds. Migraine and epilepsy. London: Butterworth Publishers Inc, $\overrightarrow{1987}$ epilepsy.

10 Terasaki T, Yamatogi Y, Ohtahara S. Electroclinical delineation of occipital lobe epilepsy in childhood In: Andermann F, Lugaresi $\mathrm{E}$ eds. Migraine and $\mathrm{Z}^{\mathrm{In}}$ : London: Butterworth Publishers Inc, 1987:125-37

11 Bickerstaff ER. The basilar artery and the migrisineepilepsy syndrome. Proc $R$ Soc Med 1962;55:167-9. 12 Basser LS. The relation of migraine and epilepsy. Brain

13 Plant GT. The fortification spectra of migraine. BMF 1986;293:1613-7.

14 Herschel JFW. Familiar lectures on scientific aspects. London: Alexander Straham, 1866:406 (citę by Plant ${ }^{13}$.

15 Gowers WR. Subjective sensations of sight and sciend, abiotrophy and other lectures. London: Churchill, 07 : $18-41$.

16 Airy $\mathrm{H}$. On a distinct form of transient hemiopsia. E⿰亻⿻ Trans $R$ Soc Lond 1870;160:247-70.

17 Ludwig BJ, Ajmone-Marjan G. Clinical ictal patter? in epileptic patients with occipital electroencephalogrä hic foci. Neurology 1975;25:463-71.

18 Miller-Fisher $\mathrm{C}$. ate life migraine accompaniments cause of unexplained transient ischemic attacks. Cañ $d \mathscr{f}$ Neurol $S c i$ i $1980 ; 7: 9-17$

19 Troost BT, Newton TH. Occipital lobe arteriovérious malformations. Arch Ophthalmol 1975;93:250-6. 